\title{
Identification of optimal reference genes for quantitative PCR studies on human mesenchymal stem cells
}

\author{
XIUYING LI ${ }^{1}$, QIWEI YANG ${ }^{1}$, JINPING BAI ${ }^{2}$, YANYAN YANG ${ }^{1}$, LINGZHI ZHONG $^{2}$ and YIMIN WANG ${ }^{1,3}$ \\ ${ }^{1}$ The Central Laboratory, China-Japan Union Hospital, Jilin University, Changchun, Jilin 130033; ${ }^{2}$ Department of Pathology, \\ Jilin University, The Key Laboratory of Pathobiology, Ministry of Education, Changchun, Jilin 130021; \\ ${ }^{3}$ Jilin Zhongke Bio-engineering Co., Ltd., Changchun, Jilin 130012, P.R. China
}

Received January 17, 2014; Accepted August 29, 2014

DOI: $10.3892 / \mathrm{mmr} .2014 .2841$

\begin{abstract}
Quantitative polymerase chain reaction (qPCR) analysis is a commonly used method for the study of mRNA expression throughout the field of mesenchymal stem cell (MSC) research. This technology is simple and sensitive; however the results may vary significantly due to the use of various reference genes (RGs) as normalizers. Therefore, the reliable use of RGs is vital for obtaining accurate results. The present study focuses on ten putative RGs for the normalization of qPCR data between human bone marrow-derived MSCs (BM-MSCs) and fetal tissue-derived MSCs (FT-MSCs). The total RNA from these two types of MSC was isolated using TRIzol reagent. cDNA was generated from the RNA via reverse transcription and subsequently analyzed by qPCR using ten common RGs as normalizers. These RGs included $18 S$, ACTB, B2M, HPRT1, GAPDH, TBP, PPIA, RPLPO, PGK1 and RPL13A. GeNorm, NormFinder and BestKeeper software were used to analyze the qPCR results by evaluating the expression stabilities of the ten candidate RGs in BM-MSCs and FT-MSCs. Consequently, several of the commonly used RGs, including $18 \mathrm{~S}, A C T B$ and $T B P$, were demonstrated to be unsuitable for normalization in these two MSCs, whereas RPL13A, B2M and PPIA were the most stable RGs and were therefore reliable for use in qPCR studies. Combining multiple RGs had no contribution towards increasing their stabilities. In conclusion, the present study revealed that RPL13A,B2M and PPIA were the optimal RGs for qPCR studies comparing BM-MSCs and FT-MSCs.
\end{abstract}

\section{Introduction}

Mesenchymal stem cells (MSCs) were initially identified as an adherent, fibroblast-like population obtained from adult bone marrow $(\mathrm{BM})$ by Friedenstein et al $(1,2)$. MSCs are able to

Correspondence to: Dr Yimin Wang, Central Laboratory, China-Japan Union Hospital, Jilin University, 126 Xiantai Street, Changchun, Jilin 130033, P.R. China

E-mail: yiminwang08@gmail.com

Key words: reference gene, real-time quantitative polymerase chain reaction, bone marrow, fetus tissue, mesenchymal stem cell differentiate into multiple lineages $(3,4)$ and are increasingly proposed as a therapeutic strategy for tissue regeneration and repair (5). Although BM has been the primary source of MSCs in the past (6-8), the use of BM-derived MSCs (BM-MSCs) is limited due to multiple factors, including the high degree of viral exposure, potential donor morbidity, as well as significant decreases in cell number and proliferation/differentiation capacity associated with age (9), and the highly invasive procedure required in order to obtain BM. Therefore, it was important to find alternative sources to provide MSCs. Further studies have identified additional MSC sources, including adult synovial membranes and the fetal liver and spleen (10-12). However, there has only been a limited number of studies on MSCs isolated from human fetuses (gestational age, 12-16 weeks). Comparison of fetal tissue-derived MSCs (FT-MSCs) (13) and adult-derived MSCs revealed that the biological activity and the differentiative and multiplication capacity of the former were greater than those of the latter (14). Comparison of the in vitro and in vivo characteristics of BM-MSCs and FT-MSCs requires analyses of their respective gene expression profiles in order to elucidate their fundamental mechanisms, including self-renewal during long-term expansion, differentiation into mature cells and tissue-repair properties.

Quantitative polymerase chain reaction ( $\mathrm{qPCR}$ ) is a commonly used technique to determine the relative change in mRNA expression of target genes. Due to the accuracy, ease of use and reproducibility of qPCR analysis, it is frequently used in MSC research. However, qPCR accuracy is influenced by various external and internal factors, including the amount of starting sample, RNA preparation, cDNA synthesis and PCR efficiency. Therefore, it is necessary to normalize gene expression levels by comparison to reference genes (RGs) as internal controls (15). An ideal RG should not be influenced by cell cycle, cell passages or experimental conditions (16); simultaneously, it should be stably expressed in various samples $(17,18)$. However, to the best of our knowledge, no single RG has been reported to be universal and completely constant. Furthermore, increasing evidence indicated that the expression levels of commonly used RGs vary significantly between cell types and experimental conditions $(19,20)$. Thus, the selection of suitable RGs for idiographic study is a prerequisite for any qPCR assay to obtain reliable results. The aim of the present study was to identify and assess the stabilities and 
Table I. Summary of reference genes used in the present study.

\begin{tabular}{|c|c|c|c|}
\hline Symbol & Name & Function & Accession number \\
\hline $18 S$ & $18 \mathrm{~S}$ ribosomal RNA & Ribosomal subunit & NM_10098.1 \\
\hline$G A P D H$ & Glyceraldehyde-3-phosphate dehydrogenase & Enzyme in glycolysis and nuclear functions & NM_002046 \\
\hline$R P L P O$ & Ribosomal protein, large, $\mathrm{P} 0$ & $\begin{array}{l}\text { Structural component of the } 60 \mathrm{~S} \text { subunit } \\
\text { of ribosomes }\end{array}$ & NM_001002.3 \\
\hline$A C T B$ & Beta-actin & Cytoskeletal structural actin & NM_001101 \\
\hline PPIA & Peptidyl-prolylisomerase A & Accelerates the folding of proteins & NM_021130.3 \\
\hline$P G K 1$ & Phosphoglycerate kinase 1 & Glycolytic enzyme & NM_000291.3 \\
\hline$B 2 M$ & Beta-2-microglobulin & Component of the MHCI molecules & NM_004048.2 \\
\hline$R P L 13 A$ & Ribosomal protein L13a & $\begin{array}{l}\text { Structural component of the } 60 \mathrm{~S} \text { ribosomal } \\
\text { subunit }\end{array}$ & NM_012423.2 \\
\hline HPRT & Hypoxanthine phosphoribosyl transferase 1 & Enzyme in purine metabolic pathway & NM_000194 \\
\hline$T B P$ & TATA box binding protein & General transcription factor & NM_003194 \\
\hline
\end{tabular}

MHCI, major histocompatibility complex class I.

reliabilities of ten RGs which are commonly used in BM- and FT-MSCs for qPCR.

Ten common RGs, including $18 S, A C T B, B 2 M, H P R T$, GAPDH, TBP, PPIA, RPLP0, PGK1 and RPL13A (Table I) were selected for the present study and their expression stabilities were analyzed using geNorm (21), NormFinder (22) and BestKeeper (23) software. The present study aimed to identify the optimal RGs for further research on BM-MSCs and FT-MSCs.

\section{Materials and methods}

MSCs. The study was approved by the Ethical Committee of China-Japan Union Hospital, Jilin University (Changchun, China). BM-MSCs were isolated from femur-derived bone marrow samples that were obtained by surgical operation (China-Japan Union Hospital) on otherwise healthy patients (aged between 18 and 43 years) following receipt of their informed consent. FT-MSCs were obtained from Jilin Zhongke Bio-engineering Co., Ltd. (Changchun, China). For all experiments, pools of the various cell types were prepared by mixing equal numbers of cells from five donors of the same passage number. Cells were not cultured for more than four passages.

\section{Identification of MSCs.}

Flow cytometric characterization of MSCs. MSCs of passage three were labeled with the following anti-human antibodies: CD14-phycoerythrin (PE), CD34-PE, CD45-fluorescein isothiocyanate (FITC), CD73-PE, CD90-FITC, CD105-peridinin chlorophyll, CD44-PE (BD Biosciences, San Jose, CA, USA). A total of $10^{6}$ labeled cells were evaluated by flow cytometry (Beckman Coulter Fc500, Brea, CA, USA) and the data were analyzed with CXP software (Beckman Coulter Fc500).

MSC differentiation potential. For the differentiation of MSCs into adipocytes and osteoblasts, cells were incubated in adipogenesis differentiation medium (StemPro ${ }^{\circledR}$ Adipogenesis Differentiation kit; Gibco-BRL, Invitrogen Life Technologies, Carlsbad, CA, USA) and osteogenesis differentiation medium
(StemPro ${ }^{\circledR}$ Osteogenesis Differentiation kit; Gibco-BRL), respectively according to the manufacturer's instructions. Adipogenic differentiation was measured by staining cells in wells with Oil Red O (Sigma-Aldrich, St. Louis, MO, USA) on day 21 of culture following fixing the cells with $5 \%$ paraformaldehyde (Beyotime, Shanghai, China) for $5 \mathrm{~min}$ at room temperature. Following 35 days of incubation, osteogenic differentiation was evaluated by staining the cells with Alizarin Red S (Alizarin S staining kit; Genmed, Shanghai, China).

RNA isolation and cDNA synthesis. Total RNA was isolated using TRIzol reagent (Invitrogen Life Technologies, Carlsbad, CA, USA) according to the manufacturer's instructions and RNA integrity was electrophoretically verified by ethidium bromide staining. RNA concentrations and A260/A280 nm absorbance ratios were measured spectrophotometrically with a Synergy HT Multi-Mode microplate reader (BioTek Instruments, Inc., Winooski, VT, USA). From 500 ng of RNA, cDNA was synthesized using an RNA PCR kit (avian myeloblastosis virus; TaKaRa, Dalian, China) according to the manufacturer's instructions. cDNA was stored at $-20^{\circ} \mathrm{C}$ until required.

Selection of candidate RGs and primer design. RGs were selected for analysis based on a literature search on the subject of RG studies in MSCs. In the present study, ten candidate RGs were selected and were as follows: $18 S, A C T B(24,25)$, B2M (26,27), HPRT, GAPDH (28-34), TBP, PPIA, RPLPO, $P G K 1, R P L 13 A$. The full name, function and accession number of the RGs assessed in the present study are listed in Table I. RGs were selected from varying functional classes, which significantly reduces the chance that the genes may be co-regulated.

Primer pairs used for qPCR were designed using primer three input (http://flypush.imgen.bcm.tmc.edu/primer/primer3_www. cgi). The qPCR primers were synthesized by Sigma Genesys (Sigma-Aldrich) with melting temperature $\left(\mathrm{T}_{\mathrm{m}}\right)$ at $60 \pm 1^{\circ} \mathrm{C}$. All primers were purified by Ultrapage (Sangon, Biotech, Shanghai, China). Primer efficiencies were determined using a 10-fold dilution series of cDNA as templates for $\mathrm{qPCR}$ reactions. An 
Table II. Primer sequences, product sizes and PCR efficiency.

\begin{tabular}{|c|c|c|c|}
\hline Gene & Primer sequences $\left(5^{\prime}-3^{\prime}\right)$ & Product size (bp) & PCR efficiency \\
\hline $18 S$ & $\begin{array}{l}\text { F-GTGGAGCGATTTGTCTGGTT } \\
\text { R-AACGCCACTTGTCCCTCTAA }\end{array}$ & 115 & 1.90 \\
\hline$G A P D H$ & $\begin{array}{l}\text { F-ATGGGGAAGGTGAAGGTCG } \\
\text { R-GGGGTCATTGATGGCAACAATA }\end{array}$ & 108 & 1.99 \\
\hline$R P L P O$ & $\begin{array}{l}\text { F-CTGGAAGTCCAACTACTTCCT } \\
\text { R-CATCATGGTGTTCTTGCCCAT }\end{array}$ & 160 & 2.74 \\
\hline$A C T B$ & $\begin{array}{l}\text { F-GAAGATCAAGATCATTGCTCCT } \\
\text { R-TACTCCTGCTTGCTGATCCA }\end{array}$ & 111 & 1.89 \\
\hline PPIA & $\begin{array}{l}\text { F-TCCTGGCATCTTGTCCAT } \\
\text { R-TGCTGGTCTTGCCATTCCT }\end{array}$ & 179 & 2.17 \\
\hline$P G K 1$ & $\begin{array}{l}\text { F-GCCACTTGCTGTGCCAAATG } \\
\text { R-CCCAGGAAGGACTTTACCTT }\end{array}$ & 102 & 2.62 \\
\hline$B 2 M$ & $\begin{array}{l}\text { F-CTATCCAGCGTACTCCAAAG } \\
\text { R-GAAAGACCAGTCCTTGCTGA }\end{array}$ & 188 & 2.08 \\
\hline RPLI3A & $\begin{array}{l}\text { F-CGAGGTTGGCTGGAAGTACC } \\
\text { R-CTTCTCGGCCTGTTTCCGTAG }\end{array}$ & 121 & 2.00 \\
\hline$H P R T$ & $\begin{array}{l}\text { F-CCTGGCGTCGTGATTAGTGAT } \\
\text { R-AGACGTTCAGTCCTGTCCATAA }\end{array}$ & 131 & 1.78 \\
\hline$T B P$ & $\begin{array}{l}\text { F-GCACAGGAGCCAAGAGTGA } \\
\text { R-GTTGGTGGGTGAGCACAAG }\end{array}$ & 174 & 2.10 \\
\hline
\end{tabular}

PCR, polymerase chain reaction; F, forward; $R$, reverse.

approximation of PCR efficiency was calculated using the slope of the calibration curve according to the following equation: $E=10^{-1 / \text { slop }}$, where 'slop' represented the linear regression slope (18). Reactions were performed in triplicate and data were analyzed by using the $2^{-\Delta \Delta \mathrm{Ct}}$ method (10). The primer sequences and corresponding amplicon sizes are listed in Table II.

$q P C R$. qPCR was performed in 96-well plates with the ABI PRISM 7500 Sequence Detection system (Perkin Elmer, Inc., Waltham, MA, USA). PCR conditions were as follows: $50^{\circ} \mathrm{C}$ for two minutes, $95^{\circ} \mathrm{C}$ for $10 \mathrm{~min}$ followed by 40 cycles of denaturation at $95^{\circ} \mathrm{C}$ for $15 \mathrm{sec}$, annealing at $58^{\circ} \mathrm{C}$ for $15 \mathrm{sec}$ and extension at $72^{\circ} \mathrm{C}$ for $30 \mathrm{sec}$ during which fluorescence was measured. Expression levels were recorded as cycle threshold $(\mathrm{Ct})$. Data were acquired using the 7500 Software (Applied Biosystems Life Technologies, Foster City, CA, USA). The mean $\mathrm{Ct}$ values of the triplicate reactions were used for data analysis.

Data analysis. Expression stabilities of the ten RGs were assessed via the three commonly used software programs geNorm, NormFinder and BestKeeper. In geNorm and NormFinder, $\mathrm{Ct}$ values were converted into relative quantities via the formula $2^{\text {-(Ct-lowest } \mathrm{Ct})}$. The raw $\mathrm{Ct}$ values were used directly for BestKeeper analysis. These three programs are based on Microsoft Excel (Microsoft Corp., Redmond, WA, USA) using various algorithms to determine the expression stability of RGs. GeNorm calculated a gene expression stability measure (M) and pairwise variation $(\mathrm{V})$ parameter. $\mathrm{M}$ is the mean pairwise variation for a given gene compared to other tested genes and stepwise exclusion of the gene with the highest $M$ value followed by recalculation was performed until the two most stable genes were left. Lower $M$ values represent higher expression stability. $\mathrm{M}=1.5$ was used as an experimental parameter. Above this value, the gene was considered to be unreliable as an RG. V was calculated to determine the minimal number of $\mathrm{RGs}$ required to normalize the expression of genes of interest. $\mathrm{V}=0.15$ was also used as an experimental parameter; below this value, the number of RGs was sufficient for valid normalization.

NormFinder computed RG stability values via an analysis of variance-based model. Lower values indicated higher stabilities. NormFinder was also able to compare inter- and intra-group variations in gene stability.

BestKeeper analyzed RG stability based on the standard deviation (SD) and coefficient of correlation (r) of all RGs. SD values were obtained from the $C t$ values of each $R G$, and $r$ values were the correlation coefficient calculated using Pearson's pair-wise correlation analyses between each RG and the geometric mean of the $\mathrm{Ct}$ values. Those genes with an SD $>1.0$ were considered to be unreliable as a stable RG and the remaining genes are ranked according to their $r$ values.

\section{Results}

Isolation and characteristics of MSCs. Human MSCs were obtained from human BM and FT. The adherent cells had fibroblastic morphologies (Fig. 1). The cell-surface antigen 
BM-MSC

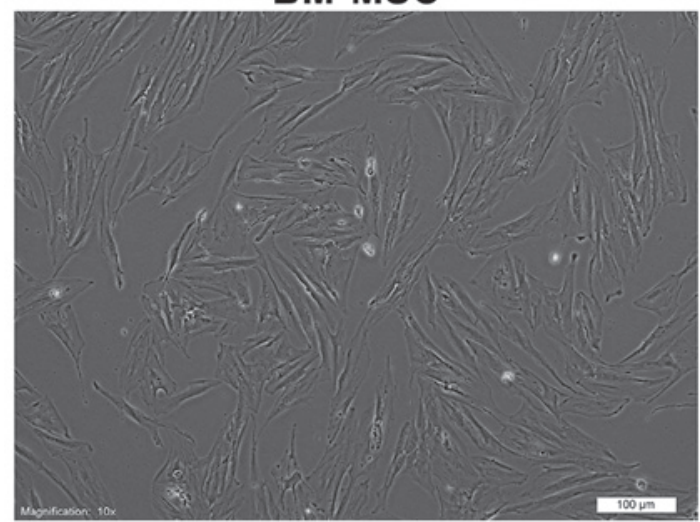

FT-MSC

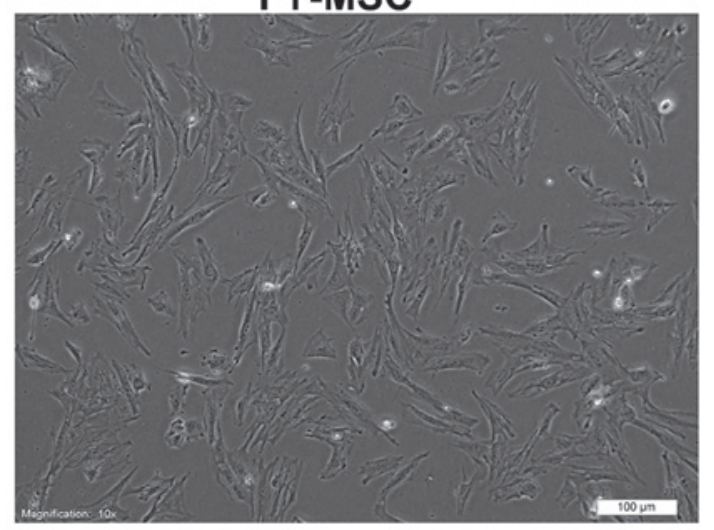

Figure 1. Morphologies of MSCs from two human tissue samples. Cells were isolated and cultured in 100-mm Petri dishes. Cells displayed a fibroblast-like shape. Cells displayed were passage three. Phase contrast magnification, x100. MSC, mesenchymal stem cell; BM, bone marrow; FT, fetal tissue.

profiles of these cells at three passages in culture were analyzed by flow cytometry. These cells were strongly positive for MSC-specific surface markers, including CD44, CD73, CD90 and CD105, but were negative for CD14, CD34 and CD45. These cells also exhibited mesenchymal differentiation potential, as assessed by culturing them in adipogenic and osteogenic medium (data not shown).

Amplification specificity and efficiency of primers. The primer sequences, corresponding amplicon sizes and PCR efficiencies of primers, are listed in Table II. The amplification performance of each primer pair was tested by qPCR. Primer specificities for qPCR were verified by dissociation curve analysis and $2 \%$ agarose gel electrophoresis. No primer-dimers or multiple bands/peaks were detected, confirming a single amplified band of a predicted size (Fig. 2). All primer pairs amplified a single PCR product of expected size, produced a slope $>-4.0$, exhibited correlation coefficients $\left(\mathrm{r}^{2}\right)>0.97$ and the corresponding qPCR efficiencies were in the range of 1.8-2.7 obtained from a 10-fold dilution series of the template cDNA. These data indicated that the amplification efficiencies of the primers analyzed reached the standard requirements of conventional qPCR.

Expression levels of RGs. The expression levels of all ten RGs were analyzed by comparison of $\mathrm{Ct}$ values using two

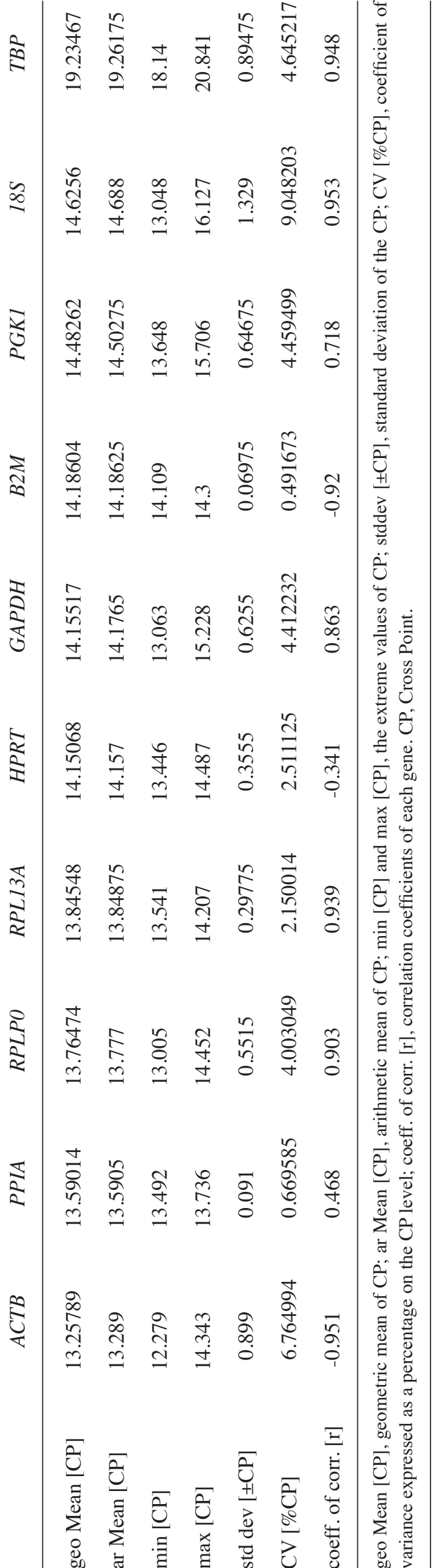




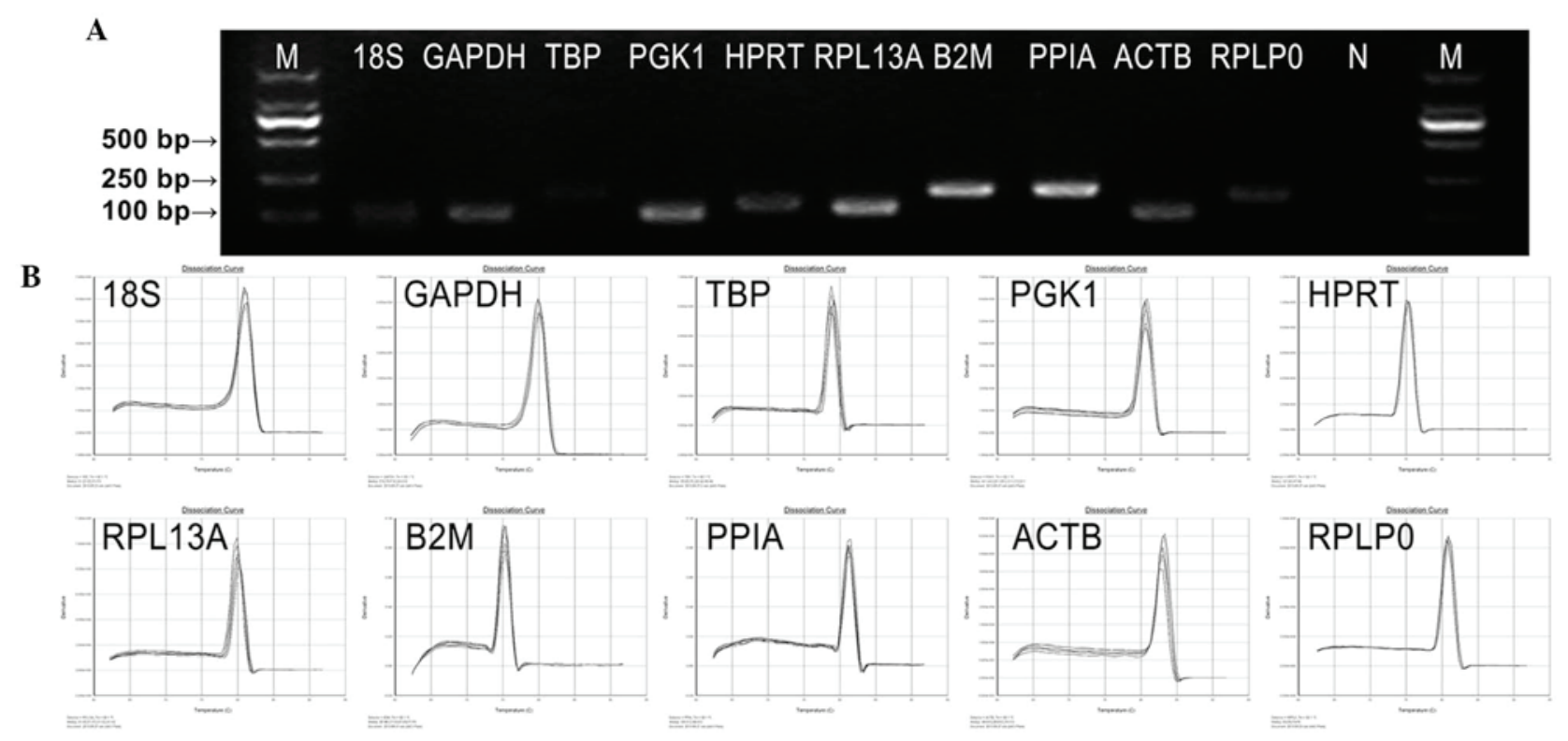

Figure 2. Specificity of primers and amplicon lengths. PCR amplification products were analyzed by agarose gel electrophoresis and dissociation curves. (A) PCR products were run through 2\% agarose gel. A single band of anticipated size indicated that the PCR product was specific. The difference in band brightness displays the different expression levels of reference genes. (B) PCR products were analyzed by their respective dissociation curves. The y-axis represents fluorescence intensity while the $\mathrm{x}$-axis shows temperature $\left(60-95^{\circ} \mathrm{C}\right)$. A single peak represented a specific PCR product. M, size markers; $\mathrm{N}$, negative control; PCR, polymerase chain reaction.

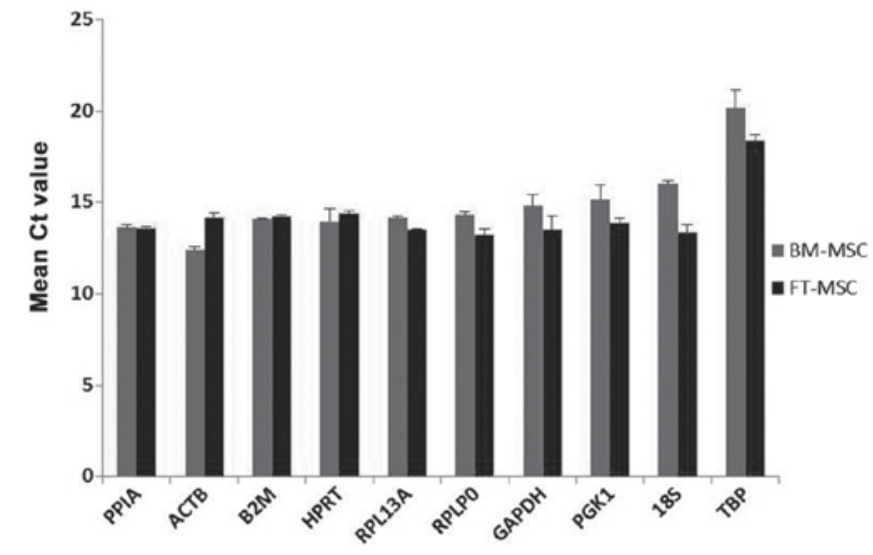

Figure 3. Expression levels of the reference genes in the two cell groups. Values are presented as the mean \pm standard deviation $(n=5)$. Ct, cycle threshold; BM-MSC, bone marrow derived mesenchymal stem cell; FT-MSC; fetus tissue derived MSC.

biological samples with three technical replicates. Fig. 3 exhibits the mean $\mathrm{Ct}$ values for each gene in two samples. All the RGs displayed $\mathrm{Ct}$ values in MSCs, ranging from 12.39 for $A C T B$ to 20.16 for TBP. Among these RGs, $A C T B$ (Ct 12.39-14.19) and PPIA (Ct 13.55-13.62) displayed the highest RNA transcription levels. The lowest RNA transcription levels were observed for $T B P(\mathrm{Ct}$ 18.37-20.16), followed by $18 S$ (Ct 13.36-16.02).The individual RGs had varying expression ranges across the samples. Among the ten RGs in the present study, $18 S$ had the greatest variation in its transcript expression levels (2.7 cycles), while PPIA and B2M had significantly lower expression variations ( 0.06 and 0.14 cycles, respectively). These $\mathrm{Ct}$ standard deviations indicated an initial hypothesis concerning the variability in expression. The RGs

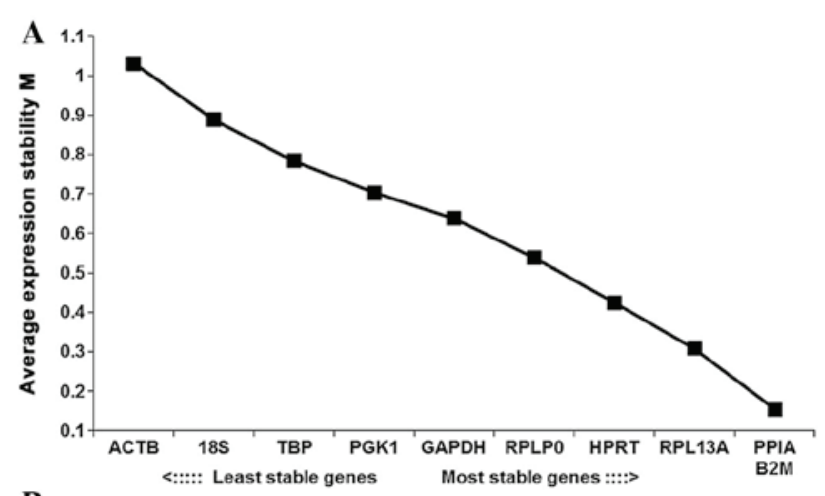

B

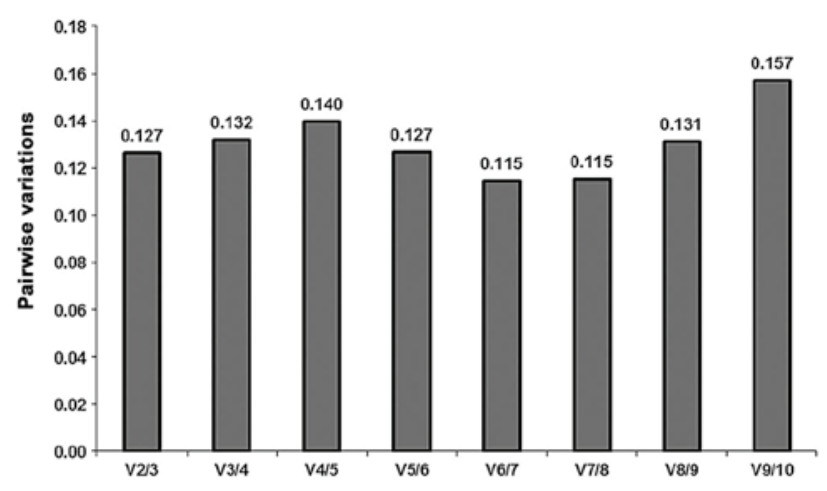

Figure 4. Selection of the most suitable RGs for normalization among samples using geNorm analysis. (A) M of the ten RGs analyzed. The x-axis from left to right indicates the ranking of the genes according to their expression stability, lower $\mathrm{M}$ values indicate higher expression stability. (B) Determination of the optimal number of RGs for normalization was conducted. Software calculated the normalization factors from at least two genes at which variable $\mathrm{V}$ defines the pair-wise variation between two sequential normalization factors. V2/3 exhibited the value below the cut-off value of 0.15 , indicating that use of two RGs for normalization is necessary, whereas the addition of a third RG is optional. M, expression stability measures; RGs, reference genes. 
Table IV. Ranking of reference gene stability.

\begin{tabular}{|c|c|c|c|c|}
\hline \multirow[b]{2}{*}{ Rank } & \multirow[b]{2}{*}{ geNorm } & \multirow[b]{2}{*}{ NormFinder } & \multicolumn{2}{|c|}{ BestKeeper } \\
\hline & & & $\mathrm{r}$ & SD \\
\hline 1 & $B 2 M, P P I A$ & $R P L 13 A$ & $A C T B$ & $B 2 M$ \\
\hline 2 & $*$ & PPIA & $T B P$ & PPIA \\
\hline 3 & RPL13A & $B 2 M$ & RPL13A & RPL13A \\
\hline 4 & $H P R T$ & $R P L P O$ & $B 2 M$ & $H P R T$ \\
\hline 5 & $R P L P O$ & $G A P D H$ & $R P L P O$ & RPLPO \\
\hline 6 & GAPDH & $H P R T$ & GAPDH & $G A P D H$ \\
\hline 7 & PGK1 & $P G K 1$ & $P G K 1$ & $P G K 1$ \\
\hline 8 & $T B P$ & TBP & PPIA & $T B P$ \\
\hline 9 & $18 S$ & $18 \mathrm{~S}$ & $H P R T$ & $A C T B$ \\
\hline 10 & $A C T B$ & $A C T B$ & & $18 S$ \\
\hline
\end{tabular}

"Rank 2 is blank since $B 2 M$ and PPIA were the the two most stable genes identified by geNorm analysis which was unable to distinguish which was first and which was second. SD, standard deviation; r, coefficient of correlation.

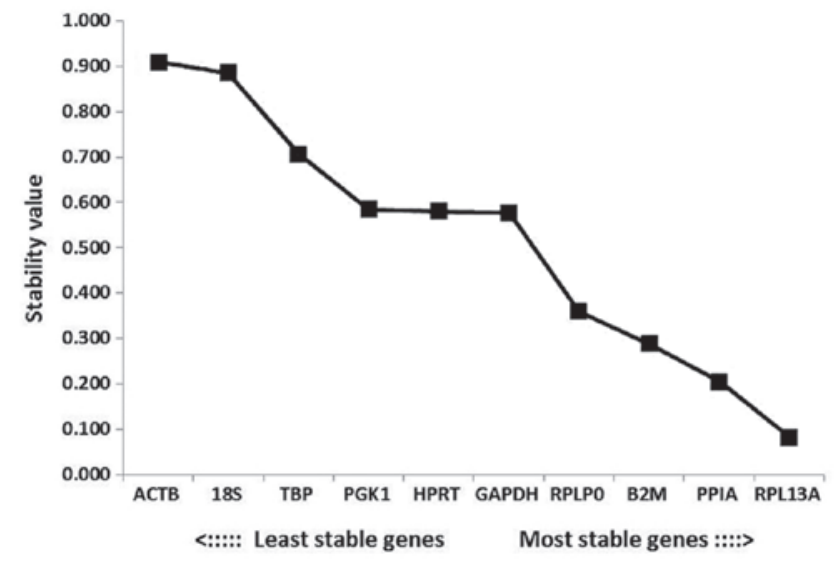

Figure 5. Expression stability values of the reference genes calculated by NormFinder. Lower stability values indicated more stably expressed genes. The $\mathrm{x}$-axis from left to right indicates the ranking of the genes according to expression stability.

were ranked from greatest to lowest variability in expression: $18 S>T B P>A C T B>P G K 1>G A P D H>R P L P 0>R P L 13 A>H P R T$ $>B 2 M>$ PPIA.

GeNorm analysis. The average stability values (M) of the ten RGs in all samples analyzed are indicated in Fig. 4A. PPIA and $B 2 M(\mathrm{M}=0.154)$ were identified as the most stably expressed RGs, while ACTB $(\mathrm{M}=1.031)$ was the least stably expressed. These ten RGs demonstrated inconspicuous variation between BM-MSCs and FT-MSCs as the M-value of each gene was below the default limit of $M \leq 1.5$. The stability ranking of the selected RGs was B2M/PPIA $>R P L 13 A>H P R T>R P L P$ $0>G A P D H>P G K 1>T B P>18 S>A C T B$. GeNorm defines a pairwise variation of 0.15 as the cutoff value, below which the inclusion of an additional RG is unnecessary (28). Here, the V2/3 value (the pairwise variation upon increasing the number of normalization factors from two to three) was 0.127 , which was below the cutoff value; hence, the use if a combination of
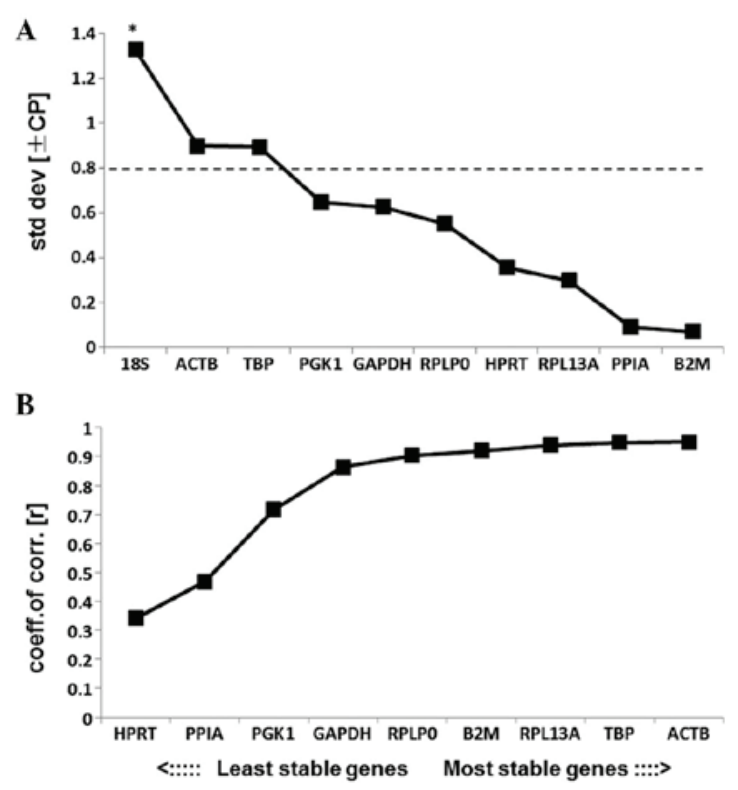

Figure 6. Evaluation of RGs using BestKeeper analysis software. (A) Std dev values of the reference genes evaluated by BestKeeper. (B) r values of RGs evaluated by BestKeeper. Higher stability values implied greater stability. std dev, standard deviation; r, coefficient of correlation; RG, reference gene.

two RGs was sufficiently stable for the analysis of BM-MSCs and FT-MSCs (Fig. 4B).

NormFinder analysis. According to the outputs from the NormFinder analysis, the most stable gene was RPL13A (stability value, 0.082 ), followed by PPIA and $B 2 M$. The most unstable genes were $A C T B, 18 S$ and $T B P$ (stability values, $0.909,0.885$ and 0.707 , respectively; Fig. 5). Among the RGs analyzed in the present study, the ranking of the stabilities according to NormFinder software was RPL13A $>P P I A>B 2$ $M>R P L P 0>G A P D H>H P R T>P G K 1>T B P>18 S>A C T B$.

The most stable combination was PPIA and RPLPO, which produced a stability value of 0.131 . 
BestKeeper analysis. The results of BestKeeper analysis are displayed in Table III. According to BestKeeper, genes with an $\mathrm{SD}>1.0$ are considered to have an unacceptable range of variation. The results of the present study indicated that all of the RGs analyzed, excluding 18S, had an SD level under 1.0 and may therefore be used as credible RGs (Fig. 6A). 18S had an SD>1.0 and was therefore eliminated from further analysis and the remaining genes were ranked according to their coefficient of correlation (r). HPRT was the most unstable RG and ACTB was the most stable RG according to the results of BestKeeper analysis (Fig. 6B). The ranking of the stabilities was $A C T B>\mathrm{TB}$ $\mathrm{P}>R P L 13 A>B 2 M>R P L P 0>G A P D H>P G K I>P P I A>H P R T$.

Comparison of software analyses. The results obtained from geNorm, NormFinder and BestKeeper were analyzed comprehensively. GeNorm and NormFinder indicated that PPIA, $B 2 M$ and RPL13A were the most stable RGs, whereas $A C T B$, $18 S$ and TBP were the least stable RGs. However, $A C T B$ was ranked as the most stable gene based on $r$ values obtained from BestKeeper analysis. A summary of the rankings produced by the three software programs is presented in Table IV.

\section{Discussion}

RGs are required to provide a scale in $\mathrm{qPCR}$ experiments. If the scale varies significantly between samples in an experiment, it loses the function of measuring gene expression in those samples. An ideal RG should be neither influenced nor regulated by experimental conditions or treatments. Increasing evidence indicated that there is no single RG that is able to be used for multiple experiments; however, an increasing number of studies suggested that a group of putative RGs for certain specific experimental setups may be recommended for future studies (35-37).

MSCs, primarily derived from BM, have been examined widely for their capacities in repairing damaged tissues (38-40). The prospective clinical applications of BM-MSCs are varied. Their ability to differentiate into desired mature cell types and additional indirect mechanisms have been recognized to have important roles in the treatment of autoimmune diseases (40). FT-MSCs, which are self-renewing and pluripotent, are a valuable research tool and have potential for use in regenerative medicine. Thus, fetal tissue provides a potential substitute to BM as a source of MSCs (41). In order to make comparisons between the mRNA expression features of two sources of MSCs, it is important to identify a standardized, reproducible set of RGs to normalize qPCR analysis.

To the best of our knowledge, the present study was the first to validate the stability of RGs used for the comparison of BM-MSCs and FT-MSCs. Expression stabilities of ten candidate RGs, including $18 S$, GAPDH, RPLPO, ACTB, PPIA, $P G K 1, B 2 M, R P L 13 A, H R P T 1$ and TBP, were estimated using three statistical algorithm software packages: geNorm, NormFinder and BestKeeper. Evaluation with geNorm as well as NormFinder indicated that B2M, PPIA and RPL13A were the most stably expressed RGs. In addition, the two programs rendered $A C T B, 18 S$ and $T B P$ the least stably expressed RGs and the rank orders were also coincident. However, the results of the analysis using BestKeeper significantly differed from those obtained using geNorm and NormFinder. BestKeeper indicated that $A C T B, T B P$ and $R P L 13 A$ were the three most stable RGs, while $18 S, H P R T$ and PPIA were least stable. Of note, $A C T B$ was ranked as most stable by BestKeeper, but least stable by geNorm and NormFinder. Rank orders obtained were expected to differ between the three software programs given their distinct statistical algorithms. For example, unlike geNorm and BestKeeper, NormFinder used a mathematical model based on assessment of intra- and intergroup variations to determine the optimal RGs and therefore showed decreased sensitivity toward co-regulation of RGs. There was no consensus regarding which was the best method. In the present study, the most stable RGs (RPL13A, PPIA and B2M) determined by geNorm and NormFinder were identical, as were the least stable genes $(A C T B, 18 S$ and $T B P$ ).

$A C T B$ is widely used as an RG to evaluate target gene expression levels in MSCs (42-46). However, in the present study, $A C T B$ was found to have the lowest stability among the selected RGs in BM-MSCs and FT-MSCs. GAPDH was previously considered as the gold standard RG, despite a lack of experimental evidence (37,47-49). However, GAPDH was ranked sixth by geNorm and fifth by NormFinder and BestKeeper in the present study. It was therefore concluded that GAPDH and ACTB were not reliable RGs for the normalization of qPCR data in BM- and FT-MSC research and they are not recommended for use throughout this field of research.

In conclusion, the present study identified RPL13A, PPIA and $B 2 M$ as suitable genes for the normalization of qPCR data and indicated that $18 S, A C T B$, and $T B P$ were unsuitable for normalization of mRNA expression levels of BM- and FT-MSCs.

\section{Acknowledgements}

The present study was supported by the National Natural Science Foundation of Jilin Province of China (no. 20130101167JC).

\section{References}

1. Friedenstein AJ, Petrakova KV, Kurolesova AI and Frolova GP: Heterotopic of bone marrow. Analysis of precursor cells for osteogenic and hematopoietic tissues. Transplantation 6: 230-247, 1968.

2. Friedenstein AJ, Chailakhyan RK and Gerasimov UV: Bone marrow osteogenic stem cells: in vitro cultivation and transplantation in diffusion chambers. Cell Tissue Kinet 20: 263-272, 1987.

3. Pittenger MF, Mackay AM, Beck SC, Jaiswal RK, Douglas R, Mosca JD, Moorman MA, Simonetti DW, Craig S and Marshak DR: Multilineage potential of adult human mesenchymal stem cells. Science 284: 143-147, 1999.

4. Keating A: Mesenchymal stromal cells. Curr Opin Hematol 13: 419-425, 2006.

5. Arthur A, Zannettino A and Gronthos S: The therapeutic applications of multipotential mesenchymal/stromal stem cells in skeletal tissue repair. J Cell Physiol 218: 237-245, 2009.

6. Young RG, Butler DL, Weber W, Caplan AI, Gordon SL and Fink DJ: Use of mesenchymal stem cells in a collagen matrix for Achilles tendon repair. J Orthop Res 16: 406-413, 1998.

7. Wakitani S, Saito T and Caplan AI: Myogenic cells derived from rat bone marrow mesenchymal stem cells exposed to 5-azacytidine. Muscle Nerve 18: 1417-1426, 1995.

8. Dennis JE and Caplan AI: Differentiation potential of conditionally immortalized mesenchymal progenitor cells from adult marrow of a H-2Kb-tsA58 transgenic mouse. J Cell Physiol 167: 523-538, 1996.

9. Rubinstein P, Rosenfield RE, Adamson JW and Stevens CE: Stored placental blood for unrelated bone marrow reconstitution. Blood 81: 1679-1690, 1993. 
10. Gullo F and De Bari C: Prospective purification of a subpopulation of human synovial mesenchymal stem cells with enhanced chondro-osteogenic potency. Rheumatology (Oxford) 52: $1758-1768,2013$

11. Joshi M, B Patil P, He Z, Holgersson J, Olausson M and Sumitran-Holgersson S: Fetal liver-derived mesenchymal stromal cells augment engraftment of transplanted hepatocytes. Cytotherapy 14: 657-669, 2012.

12. in 't Anker PS1, Noort WA, Scherjon SA, et al: Mesenchymal stem cells in human second-trimester bone marrow, liver, lung, and spleen exhibit a similar immunophenotype but a heterogeneous multilineage differentiation potential. Haematologica 88: $845-852,2003$.

13. O'Donoghue $\mathrm{K}$ and Chan J: Human fetal mesenchymal stem cells. Curr Stem Cell Res Ther 1: 371-386, 2006.

14. Jo CH, Yoon PW, Kim H, Kang KS and Yoon KS: Comparative evaluation of in vivo osteogenic differentiation of fetal and adult mesenchymal stem cell in rat critical-sized femoral defect model. Cell Tissue Res 353: 41-52, 2013.

15. Dheda K, Huggett JF, Bustin SA, Johnson MA, Rook G and Zumla A: Validation of housekeeping genes for normalizing RNA expression in real-time PCR. Biotechniques 37: 112-114, 116, $118-119,2004$

16. Radonić A, Thulke S, Mackay IM, Landt O, Siegert W and Nitsche A: Guideline to reference gene selection for quantitative real-time PCR. Biochem Biophys Res Commun 313: 856-862, 2004.

17. Bustin SA: Absolute quantification of mRNA using real-time reverse transcription polymerase chain reaction assays. J Mol Endocrinol 25: 169-193, 2000.

18. Suzuki T, Higgins PJ and Crawford DR: Control selection for RNA quantitation. Biotechniques 29: 332-337, 2000.

19. Cordoba EM, Die JV, González-Verdejo CI, Nadal S and Román B: Selection of reference genes in Hedysarum coronarium under various stresses and stages of development. Anal Biochem 409: 236-243, 2011.

20. Schmittgen TD and Zakrajsek BA: Effect of experimental treatment on housekeeping gene expression: validation by realtime, quantitative RT-PCR. J Biochem Biophys Methods 46: 69-81, 2000

21. Vandesompele J, De Preter K, Pattyn F, Poppe B, Van Roy N, De Paepe A and Speleman F: Accurate normalization of real-time quantitative RT-PCR data by geometric averaging of multiple internal control genes. Genome Biol 3: RESEARCH0034, 2002.

22. Andersen CL, Jensen JL and Ørntoft TF: Normalization of real-time quantitative reverse transcription-PCR data: a model-based variance estimation approach to identify genes suited for normalization, applied to bladder and colon cancer data sets. Cancer Res 64: 5245-5250, 2004.

23. Pfaffl MW, Tichopad A, Prgomet $C$ and Neuvians TP: Determination of stable housekeeping genes, differentially regulated target genes and sample integrity: BestKeeper - Excel-based tool using pair-wise correlations. Biotechnol Lett 26: 509-515, 2004.

24. Riekstina U, Cakstina I, Parfejevs V, Hoogduijn M, Jankovskis G, Muiznieks I, Muceniece R and Ancans J: Embryonic stem cell marker expression pattern in human mesenchymal stem cells derived from bone marrow, adipose tissue, heart and dermis. Stem Cell Rev 5: 378-386, 2009.

25. Gang EJ, Bosnakovski D, Figueiredo CA, Visser JW and Perlingeiro RC: SSEA-4 identifies mesenchymal stem cells from bone marrow. Blood 109: 1743-1751, 2007.

26. Martinez C, Hofmann TJ, Marino R, Dominici M and Horwitz EM: Human bone marrow mesenchymal stromal cells express the neural ganglioside GD2: a novel surface marker for the identification of MSCs. Blood 109: 4245-4248, 2007.

27. Pozzobon M, Piccoli M, Ditadi A, Bollini S, Destro R, André-Schmutz I, Masiero L, Lenzini E, Zanesco L, Petrelli L, et al: Mesenchymal stromal cells can be derived from bone marrow CD133+ cells: implications for therapy. Stem Cells Dev 18: 497-510, 2009.

28. Drost AC, Weng S, Feil G, Schäfer J, Baumann S, Kanz L, Sievert KD, Stenzl A and Möhle R: In vitro myogenic differentiation of human bone marrow-derived mesenchymal stem cells as a potential treatment for urethral sphincter muscle repair. Ann NY Acad Sci 1176: 135-143, 2009.

29. Tang KC, Trzaska KA, Smirnov SV, Kotenko SV, Schwander SK, Ellner JJ and Rameshwar P: Down-regulation of MHC II in mesenchymal stem cells at high IFN-gamma can be partly explained by cytoplasmic retention of CIITA. J Immunol 180: 1826-1833, 2008
30. Greco SJ, Zhou C, Ye JH and Rameshwar P: A method to generate human mesenchymal stem cell-derived neurons which express and are excited by multiple neurotransmitters. Biol Proced Online 10: 90-101, 2008

31. Trzaska KA, Reddy BY, Munoz JL, Li KY, Ye JH and Rameshwar P: Loss of RE-1 silencing factor in mesenchymal stem cell-derived dopamine progenitors induces functional maturity. Mol Cell Neurosci 39: 285-290, 2008

32. Trzaska KA, Kuzhikandathil EV and Rameshwar P: Specification of a dopaminergic phenotype from adult human mesenchymal stem cells. Stem Cells 25: 2797-2808, 2007.

33. Muguruma Y, Reyes M, Nakamura Y, Sato T, Matsuzawa H, Miyatake H, Akatsuka A, Itoh J, Yahata T, Ando K, et al: In vivo and in vitro differentiation of myocytes from human bone marrow-derived multipotent progenitor cells. Exp Hematol 31: $1323-1330,2003$

34. Greco SJ, Zhou C, Ye JH and Rameshwar P: An interdisciplinary approach and characterization of neuronal cells transdifferentiated from human mesenchymal stem cells. Stem Cells Dev 16 811-826, 2007.

35. Gresner SM, Golanska E, Kulczycka-Wojdala D, Jaskolski DJ, Papierz W and Liberski PP: Selection of reference genes for gene expression studies in astrocytomas. Anal Biochem 408: 163-165, 2011.

36. Zampieri M, Ciccarone F, Guastafierro T, Bacalini MG, Calabrese R, Moreno-Villanueva M, Reale A, Chevanne M, Bürkle A and Caiafa P: Validation of suitable internal control genes for expression studies in aging. Mech Ageing Dev 131: 89-95, 2010.

37. Raicevic G, Najar M, Stamatopoulos B, De Bruyn C, Meuleman N, Bron D, Toungouz M and Lagneaux L: The source of human mesenchymal stromal cells influences their TLR profile as well as their functional properties. Cell Immunol 270 207-216, 2011.

38. Jung KH, Yi T, Son MK, Song SU and Hong SS: Therapeutic effect of human clonal bone marrow-derived mesenchymal stem cells in severe acute pancreatitis. Arch Pharm Res: August 21, 2014 (Epub ahead of print)

39. Deng Y, Zhou H, Gu P and Fan X: Repair of canine medial orbital bone defects with miR-31-modified bone marrow mesenchymal stem cells. Invest Ophthalmol Vis Sci 55: 6016-6023, 2014.

40. Wei L, Lei GH, Yi HW and Sheng PY: Bone formation in rabbit's leg muscle after autologous transplantation of bone marrow-derived mesenchymal stem cells expressing human bone morphogenic protein-2. Indian J Orthop 48: 347-353, 2014.

41. Jones GN, Moschidou D, Abdulrazzak H, et al: Potential of human fetal chorionic stem cells for the treatment of osteogenesis imperfecta. Stem Cells Dev 23: 262-276, 2014.

42. Najar M, Raicevic G, Boufker HI, Fayyad Kazan H, De Bruyn C, Meuleman N, Bron D, Toungouz $M$ and Lagneaux L: Mesenchymal stromal cells use PGE2 to modulate activation and proliferation of lymphocyte subsets: Combined comparison of adipose tissue, Wharton's Jelly and bone marrow sources. Cell Immunol 264: 171-179, 2010.

43. Raicevic G, Rouas R, Najar M, Stordeur P, Boufker HI, Bron D, Martiat P, Goldman M, Nevessignsky MT and Lagneaux L: Inflammation modifies the pattern and the function of Toll-like receptors expressed by human mesenchymal stromal cells. Hum Immunol 71: 235-244, 2010.

44. Yañez R, Oviedo A, Aldea M, Bueren JA and Lamana ML: Prostaglandin E2 plays a key role in the immunosuppressive properties of adipose and bone marrow tissue-derived mesenchymal stromal cells. Exp Cell Res 316: 3109-3123, 2010.

45. Chen MY, Lie PC, Li ZL and Wei X: Endothelial differentiation of Wharton's jelly-derived mesenchymal stem cells in comparison with bone marrow-derived mesenchymal stem cells. Exp Hematol 37: 629-640, 2009.

46. Yoo KH, Jang IK, Lee MW, Kim HE, Yang MS, Eom Y, Lee JE, Kim YJ, Yang SK, Jung HL, et al: Comparison of immunomodulatory properties of mesenchymal stem cells derived from adult human tissues. Cell Immunol 259: 150-156, 2009.

47. Noël D, Caton D, Roche S, Bony C, Lehmann S, Casteilla L, Jorgensen C and Cousin B: Cell specific differences between human adipose-derived and mesenchymal-stromal cells despite similar differentiation potentials. Exp Cell Res 314: 1575-1584, 2008.

48. Uccelli A, Moretta L and Pistoia V: Mesenchymal stem cells in health and disease. Nat Rev Immunol 8: 726-736, 2008.

49. Pozzobon M, Ghionzoli M and De Coppi P: ES, iPS, MSC, and AFS cells. Stem cells exploitation for Pediatric Surgery: current research and perspective. Pediatr Surg Int 26: 3-10, 2010. 